\title{
La presencia y posible intervención de Julia Domna en los gobiernos de Septimio Severo y Caracalla
}

Pedro David Conesa Navarro

(University of Murcia; University of Rome Tor Vergata)

\section{The presence and possible involvement of Julia Domna in the governments of Septimius Severus and Caracalla}

\begin{abstract}
In this paper we try to analyse the role played by Julia Domna in the governments of Septimius Severus and Caracalla. Women in Rome, regardless of their social status, could not participate in the government. However, in the case of the Lepcian princeps' wife, that historiography has considered her to have interfered in government affairs is justified by the material and literary testimonies that mention her. On the basis of the main references in Cassius Dio, Herodian and the Historia Augusta, we will research whether the Augusta participated directly in imperial decisions or whether, on the contrary, her role was representative, and she was just another instrument of the Severan dynasty
\end{abstract}

\section{Keywords}

Julia Domna; female transgression; Severan dynasty; literary sources 


\section{Introducción}

No hace falta insistir, pues ha sido un tema bastante abordado por la historiografía, que, en Roma, como en cualquier otra sociedad antigua, se encontraban reducidas las acciones femeninas a lo doméstico, siendo el espacio público la parcela de actuación destinada a los varones. Esta contraposición de ambientes no significó una equiparación de responsabilidades, pues nunca fueron semejantes, ni tan siguiera complementarios. Las funciones políticas estuvieron ligadas a ellos (Cid López 2019: pp. 173-174). No obstante, la imposibilidad del ejercicio de magistraturas no fue obstáculo para que se les rindieran honores en lugares emblemáticos, además de participar en actividades relacionadas con el ámbito religioso. Ello se debió a que a través de su propio patrimonio colaboraron en la financiación de templos o diversas construcciones públicas, modificando sensiblemente la fisionomía de sus lugares de residencia hasta el punto de que, siguiendo a Martínez López (2011: p. 278), muchas veces estas actuaciones desembocaron en una feminización de las relaciones cívicas. Aunque tradicionalmente se ha tendido a vincular a acciones particulares de matronas de la nobilitas, también contamos con empresas similares sufragadas por Augustae tanto en Roma como en otros lugares provinciales. Estas últimas, también estuvieron inmersas en los espacios públicos debido a su condición de esposas, madres o hijas de los emperadores. Los principes se esforzaron por crear una imagen estable como parte fundamental de su política. De hecho, desde la Cancillería imperial, dependiente de la propia domus, se desarrollaron elementos iconográficos en los que tanto el dignatario como su familia fueron partícipes. La maternidad se convirtió en uno de los discursos más efectivos para transmitir la idea de perdurabilidad (Domínguez Arranz 2015: pp. 237-267; 2017: p. 101), siendo el espacio fundamental en el que se mostraron visibles estas damas. A partir de estas ideas generales podemos considerar que la inclusión de las Augustae en la política imperial pudo producirse de manera indirecta, a través de la utilización de su imagen por parte del dignatario o, en momentos puntuales, a través de sus propias acciones, lo que provocó que fueran censuradas por sus contemporáneos. Es precisamente la participación política de Julia Domna, siguiendo el discurso ofrecido por los autores clásicos, lo que se pretenderá analizar en este trabajo.

\section{Julia Domna. Baluarte y expresión familiar en el gobierno de Septimio Severo}

El 31 de diciembre de 192 d.C. fallecía Cómodo sin descendencia y le sucedieron Pértinax y Didio Juliano cuyos gobiernos fueron efímeros. Tras una cruenta guerra civil, Septimio Severo fue aclamado emperador por sus tropas acantonadas en Carnuntum en abril de 193 d.C. (Kienast \& Eck \& Heil 2017: p. 149). Desde el principio, Julia Domna se convirtió en uno de los baluartes más importantes de su política. Se narra en la Historia Augusta que, tras quedarse viudo de su primera mujer, Paccia Marciana, el lepcitano supo que la hija del sacerdote del culto solar de Émesa estaba predestinada a casarse 
con un rey (HA. Sev. 3, 4; 4, 1; Get. 3, 1-2; Alex. 5, 4). Este aspecto unido a la belleza de la joven fueron determinantes para que el africano deseara desposarse con ella. De hecho, este acontecimiento situado antes de que fuera nombrado princeps, podemos considerarlo como un presagio con el que en cierta manera se justificaría su posición al frente de Roma. Su ascenso a la púrpura imperial no solo respondió a su astucia y pericia militar, sino también a la supuesta predisposición de las divinidades. En este mismo sentido, se insertaría un pasaje de Dion Casio $(74 / 75 /, 3,1)$ en el que se recordaba cómo el emperador lepcitano, poco antes de producirse su enlace con Julia, soñó que Faustina la Menor les estaba preparando la cámara nupcial ( $\theta a ́ \lambda \alpha \mu o \varsigma)$ en el templo de Venus, cerca del Palatino. Por un lado, la encargada de acomodar el lecho no solo fue una representante de los Antoninos, sino que, por entonces, la esposa de Marco Aurelio gozaba de rango divino tras ser declarada diva (Priwtzer 2021: p. 446). De esta forma, se estaba manifestando que la saga inaugurada por Septimio Severo realmente era una prolongación de la dinastía precedente.

Las consultas astrológicas fueron siempre recurrentes para el emperador lepcitano si nos atenemos a la información transmitida por las fuentes literarias (Wallinger 1990: p. 83; Baharal 1992: p. 113; Smadja 2002: p. 204; Ghedini 2020: p. 26). Misma situación se podría extrapolar a sus sucesores más directos en lo concerniente a presagios sobre su destino, ${ }^{1}$ a lo que también se sumarían prácticas ligadas con la magia (Okoń 2010: p. 45). No obstante, aunque Birley (2012: p. 119) aceptó la posibilidad de que fuera verídica la noticia del horóscopo, también matizó que no se debe descartar que respondiera a una creación a posteriori, concebida en el momento en el que se estaba disputando el control del Imperio, siendo la teoría más aceptada por buena parte de la historiografía reciente (Daguet-Gagey 2000: pp. 168-169; Kemezis 2014: p. 62). A pesar de la posible manipulación del relato en cuestión, hay que tener presente que pudo decantarse por Julia Domna por el status social del que gozaba, que por entonces era superior al suyo.

La Augusta pertenecía a una familia de condición monárquica ${ }^{2}$ vinculada al templo de El-Gabal en Émesa. Por el contrario, la gens de Septimio Severo había alcanzado el grado senatorial desde hacía relativamente poco tiempo. Ello permitió que esta unión fuera interesante para él con el fin de engrandecer aún más su linaje (Ghedini 2020: p. 27; Bertolazzi 2021: pp. 452-453). La importancia de la casta sacerdotal siria se aprecia a partir de la inclusión del cognomen Bassianus, cuya raíz, basus, se traduciría por sacerdote, y que

1 La Historia Augusta señaló diferentes presagios. Sobre la muerte de Severo, HA. Sev., 22, 1-4. cf. Un ejemplo lo podemos encontrar en la sucesión imperial, en la que Julia Domna, impulsada por una fuerza divina, predijo el asesinado de su hijo menor. Cf. HA. Geta 3, 2-5. Incluso, el propio Geta intuyó su propia muerte. Cf. HA. Geta 4, 5. Sobre otros pasajes relacionados con el final del hijo menor de Severo, cf. HA. Geta, 4, 5-9. Sobre Caracalla: Hdn. 4, 12, 4-5.

2 Consideramos "monárquica" a la familia de Julia Domna debido a que el cargo sacerdotal de Émesa se transmitía de manera hereditaria desde que fue restaurado en favor de uno de sus ancestros por Augusto en el año 20 a.C., como se menciona en el propio texto. Además, como matizó Birley (2012: pp. 111-112 y 114), esta estirpe sacerdotal, a través de alianzas matrimoniales, se unió con importantes linajes reales, siendo Julia Domna descendiente, entre otras, de la casa principesca de Smasigeramo y Sohemo. 
lo portaron en sus nombres Caracalla (Septimius Bassianus), ${ }^{3}$ Heliogábalo (Varius Avitus Bassianus) y Julia Soemias (Iulia Soemias Bassiana). Por tanto, podríamos pensar que, desde el principio, Julia Domna fue utilizada en la política de su marido otorgándole ciertas prerrogativas, aunque fueran simbólicas. Turton (1974: pp. 4-5) matizó que los sectores más conservadores de la élite romana no aceptarían del todo la unión de un oficial romano con una mujer de sangre oriental, pues les recordaría a lo sucedido con Marco Antonio y Cleopatra. No obstante, los reyes de Émesa no solo fueron leales a Roma, sino que, incluso, le prestaron apoyo contra los partos. De hecho, durante un período breve de tiempo, Alexas, hermano de Yámbico I, usurpó el cargo sacerdotal y tras la victoria de Octaviano en la batalla de Actium del año 31 a.C., se restituyó de nuevo la línea dinástica a favor de un miembro de la familia originaria a la que pertenecía la esposa del princeps lepcitano (Sánchez Sánchez 2017: p. 33).

Mallan (2013: pp. 736-737), basándose para ello en la obra de Dion Casio, diferenció tres etapas en la vida de la Augusta. La primera comprendería la casi totalidad del gobierno de Septimio Severo que se caracterizó por pasar prácticamente desapercibida. No sería hasta su enfrentamiento con Plauciano cuando se insertaron algunas noticias relacionadas con la situación forzosa a la que se vio avocada a vivir tras las calumnias vertidas por el prefecto del pretorio. La consecuencia de dicho suceso fue alejarse aparentemente de la esfera pública, refugiándose en un círculo de intelectuales (D.C.75 /76/, 15, 6-7). No obstante, a pesar de esta última información, Julia Domna siguió manteniendo un papel representativo en la corte al ser la esposa del emperador y madre de los futuros herederos. Su mayor autonomía se situó en el último período de su vida correspondiente al mandato en solitario de Caracalla. Lo mismo podríamos señalar con Herodiano. Nadolny (2016: pp. 164-166) indicó que durante el gobierno de Septimio Severo las noticias referidas a Julia Domna fueron marginales y dispersas. Ello pudo deberse a que este último siguió el relato del senador bitinio. Uno de los principales aspectos de los que se diferenció radica en que Herodiano fue más descriptivo en lo concerniente a la disputa entre Caracalla y Geta, no aportando información relevante y concediéndole cierto protagonismo a la Augusta.

En la Historia Augusta tampoco se describió una participación excesiva de la esposa de Septimio Severo en la política del Imperio como muchas veces la academia científica ha considerado. A excepción de la supuesta relación sentimental de incesto mantenida con Caracalla y la visión de una madre dolorida ante la muerte de su hijo Geta, los comentarios sobre Julia Domna son escasos y mucho menos aquellos relacionados con la toma de decisiones políticas de gran calado (Wallinger 1990: p. 85; Saquete 2018: p. 324). ${ }^{4}$ No obstante, en la biografía de Claudio Albino se expone que, a pesar

3 Tal y como indicó Mastino (1981: pp. 27-28), solo se constató una inscripción con el cognomen Bassianus para Caracalla $(A E 1904,75=D$ 8914). En su amplia mayoría aparece con su denominación latina asumida en 196 d.C., al mismo tiempo que se le otorgó el título de César. Cf. Kienast \& Eck \& Heil (2017: p. 156); Galimberti (2019: p. 14).

4 Tuori (2016b: p. 185) señaló que las noticias sobre Julia Domna en la Historia Augusta muchas veces son contradictorias y bizarras. Sobre la relación de incesto. Cf. HA. Sev. 27, 7; HA. Carac. 10, 10. Herodiano $(4,9,3)$ la calificó de Yocasta, pudiendo estar relacionado con este hecho; tradición que también se aprecia en Aur. Vic. 21, 3; Eutrop. 8, 20, 2. 
de que en un primer momento Septimio Severo sopesó la posibilidad de dejar como sucesores a Pescenio Níger y Clodio Albino en caso de que le sucediera algo, finalmente se decantó por sus hijos. Estos últimos habían crecido lo suficiente para poder asumir ciertas responsabilidades. Más allá de las estrategias políticas que aceleraron el cambio de pareceres del princeps, el autor de la Historia Augusta puso de manifiesto que esta decisión fue condicionada por los consejos de su esposa (HA. Clod. Alb. 3, 4-6). En otro pasaje volvía a insistir en que en un primer momento dispuso como herederos a Níger y Albino. Sin embargo, tras la derrota del primero, no solo quiso eliminar a Clodio para así ceder el gobierno a sus vástagos, sino también porque su rival contaba con amplios apoyos en el Senado, lo que suponía un gran peligro para su estabilidad. Con el pretexto de una carta de carácter afable, en cuya despedida se mencionaban a Caracalla, Geta y la propia Julia, ordenó que cinco emisarios acabaran con la vida de su contrincante; trama que fue descubierta y que aceleró el enfrentamiento entre ambos (HA. Clod. Alb. 6, 8; 7, 1-6; 8, 1-4).

El hecho de que la Augusta pudiera intervenir en el derrocamiento de Albino tiene que ser asumido con cautela. Es cierto que debemos sopesar esta posibilidad, pues Julia intentaría eliminar todos los obstáculos que pudieran frenar las aspiraciones de Caracalla y Geta como herederos. Además, contamos con importantes antecedentes en la historia de Roma en lo que se refiere a mujeres que maniobraron en las decisiones de sus esposos e hijos. No obstante, no deja de ser problemática la hipótesis debido a la naturaleza de la fuente clásica en la que viene referida la noticia, además de algunas dificultades ligadas con la presentación de los hechos. En el último pasaje, incluso, no se llega a indicar que Julia Domna fuera determinante en la decisión adoptada por Severo. A ello se sumaría que se obtuvo la información a partir de testimonios indirectos y de autores de dudosa procedencia. Para el primer fragmento se aludía a Mario Máximo y para el segundo a Elio Junio Cordo. ${ }^{5}$ Tal y como señaló Chastagnol (1994: p. XXXIX) en la introducción a la edición francesa de la Historia Augusta que coordinó, uno de los aspectos originales de esta obra radica en que, a pesar de mantener una estructura compositiva que recordaría a textos anteriores como las Vidas de los doce césares de Suetonio, se insertaron las biografías de otros emperadores que no fueron legítimos o, directamente, que no ostentaron el poder de Roma. Ello permite que este tipo de narraciones secundarias de las que se tenía menos información como son las vidas de Clodio Albino y Pescenio Níger, se completaran con aspectos ficticios, redundantes y superfluos, dando rienda suelta a la imaginación del autor. ${ }^{6}$ Algunos individuos o, incluso, autores eran

5 Mario Máximo vivió desde finales del siglo II d.C. y principios del III d.C. Escribió biografías imperiales desde Nerva a Heliogábalo, de las que únicamente contamos con escasos fragmentos, alrededor de una treintena. Posiblemente fuera Lucio Mario Máximo Perpetuo Aureliano, hijo del procurador Lucio Mario Perpetuo, y, en cualquier caso, accedió al Senado durante el gobierno de Cómodo. Cf. Molinier-Arbo (2010: p. 203 y nota 12). Según Burian (1963: pp. 50-51), este último fue una invención, autor que también se cita en otras obras literarias como en la del propio Herodiano. Esta falsificación fue un recurso establecido por el autor de la Historia Augusta con el fin de legitimar sus datos inventados.

6 Aunque la obra está compuesta por biografías supuestamente realizadas por diferentes autores, es un tema bastante problemático y debatido. La teoría más aceptada actualmente es aquella que aboga por una única autoría. Sobre dicha problemática y bibliografía al respecto Cf. Sancho Gómez (2018: pp. 26-31). 
totalmente inventados para darle cierta legitimidad a la narración. Una de las tácticas empleadas fue intercalar un nombre común y otro novedoso, además de la combinación de nombres diferentes o incluir autores de su propia época. ${ }^{7}$ Por tanto, debido a que los pasajes en los que se aluden a Julia Domna responden a anécdotas y las fuentes de donde se obtuvo la información son de dudosa veracidad, podríamos considerar, con todas las cautelas pertinentes, que la iniciativa de Septimio Severo de eliminar a sus rivales en gran parte recayó en él y no en su esposa.

Fue la propia historiografía, condicionada por la cantidad de testimonios materiales relacionados con la Augusta (monedas, epígrafes o representaciones iconográficas), quien fomentó la imagen de una mujer poderosa y determinante. Ello no quiere decir que no interviniera en decisiones políticas; ${ }^{8}$ sobre todo durante el principado de Caracalla. Después de Livia y Agripina la Menor, Julia Domna fue de las pocas Augustae que tuvo una gran consideración bajo el mandato de su hijo (Bertolazzi 2021: p. 452). Sin embargo, consideramos que la visión "mitificada" generada en torno a su figura pudo deberse además de por el material existente y anteriormente comentado, por constituirse en modelo para sus sucesoras.

\section{La injerencia de Julia Domna en el gobierno de Caracalla}

En el catálogo de la exposición celebrada en Roma sobre la dinastía de los Severos, Roma Universalis. L'impero e la dinastia venuta dall'Africa, Cordovana (2018: p. 40) volvía a insistir en la importancia de estas mujeres en los gobiernos de sus contemporáneos. Tal y como aseguró, uno de los rasgos definitorios de esta saga imperial se basó, precisamente, en la cohesión familiar y la centralización de la idea dinástica a través de una nueva concepción ideológica. Se dieron ciertos elementos innovadores que, incluso, presagiaban mecanismos llevados a cabo tiempo después como fue la presunta "diarquía” que pretendieron materializar Caracalla y Geta. En el trascurso de las incursiones llevadas a cabo en Britania, Septimio Severo fallecería en 211 d.C., momento en el que ya se hicieron visibles las desavenencias entre los hermanos y motivó que el viaje de toda la domus imperial, con Julia Domna a la cabeza, se acelerara. Las cenizas del princeps fueron transportadas en una caja de pórfido o de oro y depositadas en el Mausoleo de

7 Sobre la invención de autores y personajes en la obra son interesantes las observaciones realizadas en Sancho Gómez (2018: pp. 31-32).

8 Wallinger (1990: p. 83) indicó que la influencia de Julia Domna sobre su marido en decisiones políticas se aprecia en el cambio de nombre de Geta a partir de un comentario de la Historia Augusta. Sobre el pasaje en cuestión. Cf. HA. Geta 1, 3-5. No obstante, tenemos que indicar que esta apreciación sobre Geta no es correcta. A partir de los testimonios epigráficos y numismáticos sabemos que Caracalla asumió el nombre de M. Aurelius Antonius Caesar, a la edad de 8 años. Este cambio se tuvo que producir entre la mitad de 195 d.C. y 4 diciembre de 196 d.C., siendo un epígrafe procedente de la Mauretania Caesariensis (AE 1916, 89) el testimonio más antiguo. Cf. Mastino (1981: p. 44); González Fernández \& Conesa Navarro (2017: pp. 137-138). Por el contrario, Geta mantuvo su nombre con la excepción del cambio de praenomen de Publius por Lucius, dado en 205 d.C. cf. Kienast \& Eck \& Heil (2017: pp. 156 y 160). 
Adriano. La entrada a la Urbs de toda la comitiva se hizo con gran solemnidad, en la que no faltaron los rituales pertinentes en honor del emperador Fallecido ${ }^{9}$.

El pretendido proyecto consistió en dividir el Imperio, quedando la parte occidental bajo dominio del primogénito, mientras que la oriental para el menor. Julia Domna, con un discurso dramático y desgarrador en el que se ensalzaron los valores maternales, fue la única que consiguió frenar las pretensiones de los herederos imperiales (Hdn. 4, 3, 8-9). Más allá de la veracidad del relato en sí y de las exageraciones del autor, es interesante valorarlo por la carga simbólica que se puede extraer del mismo. Las matronas, aunque contaran con la ayuda de pedagogos y familiares y mucho más cuanto estamos hablando de la domus divina, fueron las encargadas de la educación de los futuros ciudadanos. Esta situación trajo consigo la creación de fuertes lazos de unión con sus descendientes, siendo ellas las que, en ocasiones, llegaron a frenar o inspirar sus acciones. Sobre esta última cuestión, importante resulta el ejemplo de Cornelia. Hija y esposa fiel, madre prolífica, de formación exquisita, las capacidades intelectuales de Tiberio y Cayo Graco que se plasmaron en sus reformas fueron adquiridas gracias a la formación proporcionada por su progenitora (Cid López 2011: pp. 59-60; Cenerini 2012: p. 100). Por tanto, la inclusión de Domna en el pasaje estaba justificado a pesar de que se insistiera que los jóvenes principes estaban reunidos junto a los consejeros de su padre, quienes intentaron poner fin a la disputa sin éxito. La presencia de la Augusta en un espacio masculino podría haber sido motivo de censura por parte del autor clásico; sin embargo, Herodiano ensalzó su figura al conseguir mantener indivisible la herencia legada por Septimio Severo. El papel protagonista de Julia Domna en los acontecimientos inmediatos a la muerte de su esposo, como el traslado de las cenizas y el enfrentamiento entre Caracalla y Geta que acabamos de señalar, demostraría la consideración que tuvo en su época y la exposición pública a la que fue sometida.

Recientemente Bertolazzi (2015: pp. 419-423, 431-432) estudió las descripciones de Livia y Julia Domna que se ofrecen en la obra de Dion Casio. Ambas comparten ciertas características en lo que se refiere a su injerencia en los principados de Tiberio y Caracalla respectivamente. No obstante, se ha considerado que el relato de la Augusta del período julio - claudio estuvo supeditado a la realidad vivida por Casio, cuya posición social como senador le permitió conocer la situación de la corte imperial. De hecho, se podría decir que las noticias referentes a la esposa de Augusto muchas veces no siguen un discurso coherente, sino más bien responden a una acumulación de datos procedentes de diferentes fuentes que se articularon en función de la descripción realizada para la esposa de Septimio Severo. Tanto Livia como Julia Domna llevaron a cabo recepciones públicas, estuvieron involucradas en la correspondencia dirigida a los principes donde también se incluían sus nombres, se adentraron en lugares relevantes como los

9 Hdn. 4, 1, 1-5. En el relato de Dion Casio (76/77/, 15, 3-4), los hijos asumieron un gran protagonismo incluso antes de emprender el regreso a la capital imperial, desde el mismo momento en el que se produjo la incineración de Septimio Severo en Britania. La Historia Augusta también mencionó que fue incinerado en Britania, matizando que por todos los territorios por los que pasaba el cuerpo sin vida del princeps recibió honores. En esta última obra es donde se menciona que las cenizas se conservaban en una cajita de oro. Cf. HA. Sev. 24, 1-2. 
campamentos militares, se les atribuyeron títulos honoríficos propuestos por los propios senadores, organizaron banquetes para personalidades distinguidas e, incluso, en un momento dado sopesaron convertirse en las únicas gobernantes, aunque realmente no les estaba permitido por su condición de género. No obstante, a pesar de este paralelismo aparente, se aprecian divergencias en lo concerniente a la correspondencia y en el deseo de ejercer el poder en solitario. Además de no apreciarse ninguna fractura entre Domna y su hijo, aspecto que sí se dio con Tiberio y Livia, y que no solo fue mencionado por Casio, la esposa de Severo únicamente aspiró a gobernar una vez muerto Caracalla. No obstante, hay que tener presente las intenciones del autor, pues las noticias referentes a Julia Domna pudieron actuar como contraposición y crítica a la manera en la que ejerció el poder su hijo. El fracaso del primogénito del princeps lepcitano fue la consecuencia de desatender los asuntos de gobierno y por no aceptar los consejos de su madre (Gascó 1988: p. 64; Tuori 2016b: p. 184); hipótesis que consideramos coherente y que a continuación trataremos de demostrar.

Julia Domna, además de atender peticiones y ocuparse de la correspondencia en nombre de Caracalla, lo acompañó durante las campañas bélicas llevadas a cabo en Nicomedia en el invierno de 214-215 d.C., como previamente hizo con su marido (D.C. 77 /78/, 18, 2-3; Levick 2007: pp. 101-102; Ghedini 2020: pp. 139-140). En palabras de Tuori (2016b: pp. 180-182), a partir de este pasaje de Casio se demostraría la aparente ineficacia e ineptitud del emperador. Se ha interpretado que Julia Domna no solo gobernó de facto, sino que, incluso, pudo participar en los tribunales, aunque fuera en representación de su hijo. Esta información parece recordar a la situación desarrollada durante la etapa julio - claudia; sin embargo, es importante subrayar que en este caso adquiere un matiz importante al ser Dion Casio contemporáneo a los hechos y uno de los que formó parte de la comitiva de la expedición, pues el hecho de que fuera originario de la zona fue determinante para que Caracalla tomara la decisión de que los acompañara, presuponiéndose, por tanto, cierta veracidad en sus comentarios (Gascó 1988: p. 82; Tuori 2016b: p. 182; Okoń 2013: p. 257; Burden-Strevens 2020: p. 28). El emperador, como cabeza visible, la más importante autoridad legal, judicial, legislativa y administrativa, debería haber asumido dichas responsabilidades que en principio fueron legadas a su madre. No obstante, a pesar de este protagonismo conferido a la Augusta, no hay mención en el Código de Justiniano ni tampoco en ninguna fuente epigráfica o papirológica en la que se exprese que ella fue la autora de alguna constitución imperial (Tuori 2016b: p. 181).

Resulta imposible aceptar que el princeps acaparara todas las peticiones y requerimientos, además de participar en diversas celebraciones y liderar las huestes cuando había algún enfrentamiento. Para ello se constituyó un amplio cuerpo burocrático ex professo con amplios conocimientos legales, con el fin de agilizar todos las cuestiones administrativas o judiciales, donde tendríamos que incluir la creación en época de los Severos del cargo del iudex uice Caesaris (Mennen 2011: pp. 41-42). Para la correspondencia se encargaron el ab epistulis Graecis et Latinis, o ab respondis, que dirigían a un nutrido grupo de libertos, equites y esclavos. No obstante, pese a todo, el princeps sancionó todos los dictámenes y las misivas iban con su rúbrica (Honoré 1994: p. 1). Por tanto, estas funciones, tanto legales como burócratas atribuidas a Julia Domna, decía Levick 
(2007: pp. 95-96), que es poco probable que tuvieran un carácter oficial si tenemos presente la prohibición a las mujeres para desempeñar magistraturas, además de que sería impropio que una Augusta asumiera responsabilidades de las que se ocupaban libertos o caballeros.

En lo que respecta a la reputación adquirida por Caracalla en materia legal, podríamos decir que es contradictoria. Herodiano matizó que, aunque bien es cierto que no dedicó mucho tiempo a los asuntos de gobierno, sus razonamientos fueron reflexivos gracias al asesoramiento con el que siempre contó (Hdn. 4, 7, 2). Además, matizó que la correspondencia fue encomendada a Macrino como prefecto del pretorio (Hdn. 4, 12, 3-8), que no encajaría precisamente con el discurso proporcionado por Dion Casio. Se han contabilizado 264 rescriptos pertenecientes a su principado, en algunos de ellos se aprecia una especial simpatía hacia el sector ecuestre. Las deliberaciones dadas fueron complejas, lo que contrastaría con la imagen descuidada transmitida por los autores clásicos (Tuori 2016a: pp. 270-271), a lo que habría que añadir un hito legal como fue la Constitutio Antoniniana promulgada en 212 d.C. (D.C. $77 / 78 /, 9$, 5). Por tanto, la pregunta sería si podemos darle crédito a la información transmitida por Casio o el hecho de que dijera que Domna participó en los asuntos de gobierno fue una artimaña para desacreditar al emperador. Tuori (2016b: pp. 194-196) subrayó al respecto que es complejo conocer la realidad, aunque no hay motivos para negar el contenido del senador bitinio. Aunque en principio las mujeres no podían asumir este tipo de funciones, contamos con antecedentes y lo que es más importante, habría que tener presente la concepción que se tenía del princeps, cuya autoridad suprema le permitió modificar toda norma según sus propios intereses. Además, la autoridad social de Julia Domna motivó que las élites locales enviaran peticiones directamente a la Augusta con el ánimo de que intercediera a su favor ante su hijo (Kettenhofen 1979: p. 19).

La respuesta de Julia Domna a una carta enviada previamente por las autoridades de Éfeso y también la contestación ofrecida por Caracalla fueron expuestas en una placa de mármol que fue hallada en el Teatro de la ciudad (I Éph. 2, 212; AE 1966, 430; Kettenhofen 1979, pp. 17-18). En ella se especifica el dictamen del emperador en lo que se refiere a la concesión de una tercera neokoría ( $v \varepsilon \omega ́ \kappa о \rho о \varsigma)$. Por otro lado, la Augusta reconocía la preeminencia del enclave en cuanto a su belleza, sus dimensiones y, sobre todo, por constituirse en una de las cunas culturales más importante de la corriente filosófica de la Segunda Sofística. En ningún momento se alude a una intervención directa de Julia Domna (Levick 2007: p. 96; Gangloff 2013: p. 33; Schöpe 2014: p. 193), lo que hace que la afirmación de Langford (2013: 21-22) de que este ejemplo confirmaría que la esposa de Septimio Severo había conseguido una representación semioficial sin precedentes en un miembro de la familia imperial, podría resultar un tanto arriesgada. De hecho, así lo advirtió Kettenhofen (1979: p. 18) tras una crítica historiográfica a algunos trabajos que afirmaron un amplio poder para la esposa de Septimio Severo y que para ello se basaron en el relato de Dion Casio y en el testimonio epigráfico de Éfeso. Decía el autor que, aunque es innegable la influencia moral que pudo tener sobre su hijo, tampoco hay que sobrevalorar su posición.

La primera parte del texto es el mensaje de la Augusta en el que se manifiesta su deseo de que de los requerimientos realizados fueran atendidos por su hijo. Después, tras 
el nombre del emperador, se informa que son aceptadas sus peticiones. El hecho de que en el texto se mencione a Julia Domna en una posición anterior al de Caracalla permitiría sugerir que los ciudadanos de Éfeso enviaron directamente la misiva a ella y no al princeps, otorgándole, por tanto, cierto margen de maniobra en la decisión de qué aspectos serían tramitados por la Cancillería imperial de los que no (Bertolazzi 2015: p. 422; 2021: p. 455). Esta noticia se desprende incluso a partir de una referencia de Casio en la que se detallaba que Flavio Materniano, comandante de las tropas urbanas, envió una carta a Caracalla para informarle que una profecía de un adivino de África vaticinaba que sería sustituido por Macrino y Diadumeno. La emisiva fue desviada a Antioquía, lugar en el que se encontraba Domna, ya que el princeps por entonces estaba en territorio enemigo y no podía atender a los requerimientos que le solicitaban (D.C. $78 / 79 /, 4,1-3)$. Por otro lado, el senador bitinio también matizó que en la correspondencia de Caracalla dirigida al Senado además de su nombre, también se incorporaron el de su madre y el de las legiones y se indicaba que ella, al igual que él, se encontraba bien; fórmula que estaba reservada en principio para los emperadores. A diferencia de Livia, que estuvo en las emisiones de su hijo en un período breve de tiempo, Julia Domna gozó de dicho privilegio hasta el final de sus días (Bertolazzi 2015: pp. 421-422).

No obstante, aunque es cierta la posible influencia de la Augusta, sigue siendo difícil asegurar un poder real $\mathrm{u}$ oficial, tal y como recientemente ha subrayado Thruschnegg (2021: p. 415). Para empezar, como hemos insistido, las decisiones recaían en el princeps, a lo que se añadiría lo expuesto por Beckmann (2002: p. 277) de que estas mismas fuentes indicaron constantemente que Caracalla no siguió los consejos de su madre. Además, independientemente de que fuera ella la que maniobró en la correspondencia, sus destinatarios no lo conocerían, y, posiblemente, el hecho de que en las emisivas dirigidas a Éfeso sí que se especificó la intervención directa del emperador y de su madre, motivó que fuera fijado su contenido en una inscripción con el fin de que quedara registrado para la posteridad este hecho excepcional. En lo que se refiere a la recepción de comitivas o que Caracalla enviara cartas al Senado con el nombre de su madre junto al de las legiones, formaría parte de la estrategia política inaugurada por su padre de mostrar fortaleza a partir de la domus divina, cuyos dos únicos integrantes por entonces fueron él y Julia Domna, así como su proximidad al sector militar que le proporcionaba estabilidad y que Septimio Severo, antes de morir, ya les recomendó a sus hijos que no descuidaran a los soldados (DC. $76 / 77 /, 15,2$ ).

Por último, no podemos desdeñar el contexto histórico y social que fagocitó que el autor describiera esta contraposición de comportamientos entre Caracalla y su madre en el pasaje referido a Nicomedia. Aunque durante un tiempo se pensó que el senador bitinio perteneció al grupo selecto de intelectuales con el que se rodeó la Augusta, cada vez más son los estudios que apuntan en la dirección contraria. Además de ser pocos los textos que aluden a este círculo y las condiciones políticas que motivaron su creación, decía Gascó (1988: pp. 63-64) que los calificativos empleados por Casio para referirse a ella no fueron del todo positivos, pues especuló que tuvo un oscuro linaje, que legó a su hijo Caracalla su astucia y que se comportaba con poco atrevimiento. Además, el senador bitinio menospreció en ocasiones a figuras importantes de la filosofía 
con algunas excepciones. Un ejemplo fue Apolonio de Tiana, al que calificó como goes y mago, siendo precisamente este último, una de las figuras más importantes del conjunto de personalidades ligado a Julia Domna. ${ }^{10}$ Por tanto, todo parece indicar que el senador bitinio exageró la presencia de la Augusta en los asuntos de gobierno con el fin de censurar la actitud de Caracalla.

Un princeps no debía tener malos hábitos y mucho menos trasladarlos a su gobierno. Debía ser ajustado, comedido, no abusar de su poder y compartirlo con la nobilitas. De hecho, tal y como recodó Galimberti (2019: p. 116), durante esta estancia invernal en Nicomedia, Dion Casio hizo alusión a la construcción de circos y anfiteatros en los que se produjeron juegos gladiatorios y matanzas de animales. La proyección de estos grandes edificios, así como aquellas residencias o palacios que se construyeron en este período, algunos de ellos sin llegar a utilizarse, fueron sufragados con el capital de los senadores y la nobilitas local, queriendo con ello evidenciar un derroche innecesario, cuyo responsable fue el propio emperador. Solo atendió a las necesidades del ordo equester encaminadas a la construcción de máquinas de guerra capaz de ser desmontadas para su fácil trasporte, así como al adiestramiento de las tropas, especialmente la considerada falange macedónica, intentando con ello imitar de manera ridícula a Alejandro Magno (D.C. 77 $/ 78 /, 9,5-7)$ e ignorando las expectativas de los senadores que, al fin y al cabo, era lo que verdaderamente le importaba al autor.

Sobre la muerte de Julia Domna hay dos versiones. Herodiano $(4,13,8)$ se limitó a indicar que las cenizas de Caracalla fueron enviadas a Antioquía donde se encontraba su madre. Tras perder a sus dos hijos en circunstancias parecidas, decidió suicidarse de inedia por voluntad propia o por un mandato imperial. Más interesante por el argumento que estamos tratando es el relato de Dion Casio $(78 / 79 /, 23,1-6)$. Al igual que en el caso anterior, se mencionó que se encontraba en Antioquía cuando recibió la noticia del fallecimiento de su hijo. En un primer momento sopesó la posibilidad del suicidio tras pensar que su posición social podría verse reducida. Viendo que Macrino no había dispuesto nada en detrimento de su situación, intentó asumir el gobierno del Imperio. No obstante, temiendo verse privada de su distinción de Augusta tras ser obligada a regresar a Émesa y tras conocer la reputación de Caracalla, se dejó morir, aunque es probable que su fallecimiento fuera por causa de un cáncer de mama (Bertolazzi 2021: p. 455). Resulta difícil conocer si entre los planes de la esposa de Septimio Severo estaba gobernar en solitario; hipótesis un tanto artificial para la mentalidad de la época, siendo además la comparación con las reinas orientales, Semíramis y Niócris, un recurso con el que, además de demostrar la intelectualidad de Casio y la contraposición del componente oriental frente a la mentalidad patriarcal romana, una exageración con la que intentaba

10 Con parámetros similares Kettenhofen (1979: p. 10) y más recientemente Mallan (2013: pp. 747-748) puntualizaron que Casio fue crítico con la Augusta, especialmente durante la última etapa de su vida al calificarla como fría y calculadora. Los pasajes a los que hizo referencia Gascó son los siguientes: sobre el origen humilde o plebeyo: D.C. $78 / 77 /, 24,1$. Sobre la astucia legada a Caracalla que también viene referida en otra ocasión como una connotación peyorativa: D.C. $77 / 78 /, 6,1$ a; $77 / 78 /$, 10, 2). No obstante, siguió mencionando Kettenhofen (1979: pp. 11-12), que cierta simpatía se apreciaría en el discurso de Casio sobre la Augusta, debido a los problemas que tuvo que asumir por la actitud adoptada por Plauciano y Caracalla. 
concluir la vida de una mujer transgresora que, aparentemente, no cumplió sus roles de género (Kettenhofen 1979: pp. 12-13; Bleckmann 2002: pp. 278-279; Moscovich 2004: pp. 364-366; Mallan 2013: pp. 752-755; Burden-Strevens 2020: pp. 142-143). ${ }^{11}$

\section{Conclusiones}

A lo largo del trabajo, podemos concluir que a partir de la información trasmitida por los autores clásicos encontramos un papel mucho más activo de Julia Domna en la política de Caracalla que en la de su marido. No obstante, la consideración social que tuvo la Augusta incluso antes de que Septimio Severo fuera aclamado emperador, se mantuvo también durante el gobierno de su hijo. De ahí su posición próxima, más si tenemos presente las circunstancias con las que su primogénito alcanzó la púrpura. Ello permitió no solo que las élites provinciales, como es el caso de las de Éfeso, mostraran gran respecto a la Augusta, sino que también pudo asumir cierto protagonismo en la política imperial. Bien es cierto, que a lo largo de nuestra exposición hemos insistido que no se debe sobrevalorar su figura, pues a pesar de formar parte de la política ideológica imperial, las prerrogativas gubernamentales las siguió conservando el princeps y lo sucedido en Nicomedia, donde Dion Casio señaló que despachaba comitivas reales, así como la correspondencia oficial, es posible que fuera una crítica a su manera de gestionar el Imperio, dando prioridad a los asuntos bélicos frente a los intereses senatoriales.

\section{Bibliografía}

Baharal, D. (1992). The Portraits of Julia Domna from the Years 193-211 A.D. and the Dynastic Propaganda of L. Septimius Severus. Latomus, 51(1), 110-118.

Bertolazzi, R. (2015). The Depiction of Livia and Julia Domna by Cassius Dio: Some Observations. Acta Antiqua Academiae Scientiarum, 55(1), 413-432.

Bertolazzi, R. (2021). Women in the Severan Dynasty. In E. D. Carney, \& S. Müller (Eds.), The Routledge Companion to Women and Monarchy in the Ancient Mediterranean World (pp. 452-462). London - New York: Routledge.

Birley, A. R. (2012). Septimio Severo. El emperador africano. Madrid: Gredos.

Bleckmann, B. (2002). Die severische Familie und die Soldatenkaiser. In H. Temporni-Gräfin Vitzthum (Ed.), Die Kaiserinnen Roms. Von Livia bis Theodora (pp. 265-339). München: Verlag C. H. Beck.

Burden-Strevens, C. (2020). Cassius Dio's Speeches and the Collapse of the Roman Republic. The Roman History, Books 3-56. Leiden - Boston: Brill.

Burian, J. (1963). Zur Historischen Glaubwürdigkeit der Gordiani tres in der Historia Augusta. In Atti del colloquio patavino sulla Historia Augusta (pp. 41-66). Roma: L'Erma di Bretschneider.

Cenerini, F. (2012). Sessualità e Imperium: la trasgressione femminile alla fine dell'età repubblicana. Lectora, 18, 99-111.

11 Sobre la valoración moral. Cf. DC. 78 /79/, 24, 1-3. 
Chastagnol, A. (1994), I. Le problème de l'Histoire Auguste et son historiographie. In Idem (Ed.), Histoire Auguste. Les empereurs romains des II'et III'siècles (pp. IX-CLXXVII). Paris: Robert Laffont. Cid López, R. M.a (2011). La matrona y las mujeres de la Roma antigua. Un estereotipo femenino a través de las imágenes religiosas y las normas legales. In D. Hidalgo Rodríguez, N. Cubas Martín, \& M. ${ }^{a}$ E. Martínez Quinteiro (Eds.), Mujeres en la Historia, el Arte y el Cine. Discursos de género, variantes de contenido y soportes: de la palabra al audiovisual (pp. 55-70). Salamanca: Ediciones Universidad de Salamanca.

Cid López, R. M.` (2019). Domus, mujeres y género. Imágenes y espacios de la dependencia femenina. In M. García Sánchez, \& R. S. Garraffoni (Eds.), Mujeres, género y estudios clásicos: un diálogo entre España y Brasil / Mulheres, gênero e estudos clássicos: um diálogo entre Espanha e Brasil (pp. 173-191). Barcelona: Universitat de Barcelona Edicions.

Cordovana, O. D. (2018). I Severi. In A. D’Alessio, C. Panella, \& R. Rea (Eds.), I Severi Roma Universalis. L'impero e la dinastia venuta dall'Africa (pp. 36-47). Milano: Electa.

Daguet-Gagey, A. (2000). Septime Sévère. Rome, l'Afrique et l'Orient. Paris: Biographie Payot.

Domínguez Arranz, A. (2015). Tejiendo su propia identidad. La presencia pública de la matrona imperial romana. In A. Domínguez Arranz, \& R. M. ${ }^{a}$ Marina Sáez (Eds.), Género y enseñanza en la Historia. Silencios y ausencias en la construcción del pasado (pp. 237-267). Madrid: Sílex.

Domínguez Arranz, A. (2017). Imágenes del poder en la Roma imperial: política, género y propaganda. Arenal. Revista de historia de las mujeres, 24(1), 99-131.

Galimberti, A. (2019). Caracalla. Roma: Salerno Editrice.

Gangloff, A. (2013). Les cités grecques et l'ouverture sur la mer à l'époque impéraiale: enjeux et représentations. In E. Guerber, \& G. Le Bouëdec (Eds.), Ports et cités aux époques ancienne, médiévale et moderne (pp. 23-39). Rennes: Presses universitaires de Rennes.

Gascó, F. (1988). Casio Dion. Sociedad y política en tiempos de los Severos. Madrid: Coloquio Editorial.

Ghedini, F. (1984). Giulia Domna tra Oriente e Occidente. Le fonti archeologiche. Roma: L'Erma di Bretschneider.

Ghedini, F. (2020). Giulia Domna. Una siriaca sul trono dei Cesari. Roma: Carocci editore.

González Fernández, R., \& Conesa Navarro, P. D. (2017). La dinastía severa y el nomen Aurelius. Septimio Severo y la gens Aurelia. Athenaeum, 105(1), 137-152.

Gorrie, C. (2004). Julia Domna's Building Patronage, Imperial Family Roles and the Severan Revival of Moral Legislation. Historia, 53(1), 61-72.

Gorrie, C. (2007). The Restoration of the Porticus Octaviae and Severan Imperial Policy. Greece Eै Rome, 54(1), 1-17.

Honoré, T. (1994). Emperors and Lawyers. Oxford: Clarendon Press.

Kemezis, A. M. (2014). Greek Narratives of the Roman Empire Under the Severans. Cassius Dio, Philostratus and Herodian. Cambridge: Cambridge University Press.

Kettenhofen, E. (1979). Die syrischen Augustae in der historischen Überlieferung. Ein Beitrag zum Problem der Orientalisierung. Bonn: Rudolf Habelt Verlag GMBH.

Kienast, D., Eck, W., \& Heil, M. (2017). Römische Kaisertabelle. Grundzüge einer römischen Kaiserchronologie (6 $6^{\text {th }}$ ed.). Darmstadt: Wissenschaftliche Buchgesellschaft.

Langford, J. (2013). Maternal Megalomania. Julia Domna and the Imperial Politics of Motherhood. Baltimore: The Johns Hopkins University Press.

Levick, B. (2007). Julia Domna. Syrian Empress. London - New York: Routledge. 
Mallan, C. T. (2013). Cassius Dio on Julia Domna: A Study of the Political and Ethical Functions of Biographical Representation in Dio's Roman History. Mnemosyne, 66(4-5), 734-760.

Martínez López, C. (2011). Amantissima civium suorum: Matronazgo cívico en el Occidente romano. Arenal, 18(2), 277-307.

Mastino, A. (1981). Le titolature di Caracalla e Geta attraverso le iscrizioni (indici). Bologna: Editrice CLUEB.

Mennen, I. (2011). Power and Status in the Roman Empire AD 193-284. Leiden - Boston: Brill.

Molinier-Arbo, A. (2010). Histoire d'un palimpseste: le Nero et le Caligula de Suétone dans la Vita Commodi de l'Histoire Auguste. Dialogues d'histoire ancienne, Supplément, 4(1), 201-221.

Moscovich, M. J. (2004). Cassius Dio's Palace Source for the Reign of Septimius Severus. Historia, 53(3), 356-368.

Nadolny, S. (2016). Die severischen Kaiserfrauen. Stuttgart: Franz Steiner Verlag.

Okoń, D. (2010). Mariage de Septime Sévère avec Julia Domna. Au fond des stratégigies matrimoniales des familles sénatoriales romaines à la charnière des IIeet IIIesiècle. Eos, 97, 45-62.

Okoń, D. (2013). Caracalla and his collaborators. Mnemon, 13, 253-262.

Priwtzer, S. (2021). The Faustinas. In E. D. Carney, \& S. Müller (Eds.), The Routledge Companion to Women and Monarchy in the Ancient Mediterranean World (439-451). London - New York: Routledge.

Sánchez Sánchez, I. (2017). La introducción del culto de El Gabal en Roma. Madrid - Salamanca: Signifer.

Saquete, J. C. (2018). La Historia Augusta y las mujeres. In P. Pavón (Ed.), Marginación y mujer en el Imperio romano (pp. 315-322). Roma: Edizioni Quasar.

Schöpe, B. (2014). Der römische Kaiserhof in sverischer Zeit (193-235 n. Chr.). Stuttgart: Franz Steiner Vergag.

Sancho Gómez, M. P. (2018). La religión del autor de la "Historia Augusta". Murcia: CEPOAT.

Smadja, E. (2002). Divination et signes de pouvoir dans l'Histoire Auguste. In M. Fartzoff, E. Smadja, \& É. Geny (Eds.), Pouvoir des hommes, signes des Dieux dans le monde antique. Actes des rencontres de Besançon (1999-2000) (pp. 191-218). Besançon: Institut des Sciences et Techniques de l'Antiquité.

Truschnegg, B. (2021). Feminine, influential and different? The Presentation of Julia Domna. In K. Droß-Krüpe, \& S. Fink (Eds.), Powerful Women in the Ancient World. Perception and (Self)Presentation. Proceedings of the $8^{\text {th }}$ Melammu Workshop, Kassel, 30 January - 1 February 2019 (pp. 413-432). Münster: Zaphon.

Tuori, K. (2016a). The Emperor of Law. The Emergence of Roman Imperial Adjudication. Oxford: Oxford University Press.

Tuori, K. (2016b). Judge Julia Domna? A Historical Mystery and the Emergence of Imperial Legal Administration. The Journal of Legal History, 37(2), 180-197.

Turton, G. (1974). The Syrian Princesses. The Women who Ruler Rome, AD. 193-235. London: Cassell. Walinger, E. (1990). Die Frauen in der Historia Augusta. Wien: Österreichischen Gesellschaft für Archäologie. 
Dr. Pedro David Conesa Navarro / pedrodavid.conesa@um.es

Department of Prehistory, Archaeology, Ancient History, Medieval History and Historiographical Science and Techniques

University of Murcia, Faculty of Arts

Calle Santo Cristo, s/n, 30001, Murcia, Spain

This work can be used in accordance with the Creative Commons BY-SA 4.0 International license terms and conditions (https://creativecommons.org/licenses/by-sa/4.0/legalcode). This does not apply to works or elements (such as image or photographs) that are used in the work under a contractual license or exception or limitation to relevant rights 
